\title{
BMJ Open Community pharmacy lifestyle intervention to increase physical activity and improve cardiovascular health of men with prostate cancer: a phase II feasibility study
}

To cite: Lemanska A, Poole K, Griffin BA, et al. Community pharmacy lifestyle intervention to increase physical activity and improve cardiovascular health of men with prostate cancer: a phase II feasibility study. BMJ Open 2019;9:e025114. doi:10.1136/ bmjopen-2018-025114

- Prepublication history and additional material for this paper are available online. To view these files, please visit the journal online (http://dx.doi org/10.1136/bmjopen-2018025114).

Received 2 July 2018

Revised 12 0ctober 2018 Accepted 26 March 2019

Check for updates

(C) Author(s) (or their employer(s)) 2019. Re-use permitted under CC BY-NC. No commercial re-use. See rights and permissions. Published by BMJ.

For numbered affiliations see end of article.

Correspondence to Agnieszka Lemanska; a.lemanska@surrey.ac.uk

\section{ABSTRACT}

Objectives To assess the feasibility and acceptability of a community pharmacy lifestyle intervention to improve physical activity and cardiovascular health of men with prostate cancer. To refine the intervention.

Design Phase II feasibility study of a complex intervention.

Setting Nine community pharmacies in the UK. Intervention Community pharmacy teams were trained to deliver a health assessment including fitness, strength and anthropometric measures. A computer algorithm generated a personalised lifestyle prescription for a homebased programme accompanied by supporting resources. The health assessment was repeated 12 weeks later and support phone calls were provided at weeks 1 and 6 . Participants 116 men who completed treatment for prostate cancer.

Outcome measures The feasibility and acceptability of the intervention and the delivery model were assessed by evaluating study processes (rate of participant recruitment, consent, retention and adverse events), by analysing delivery data and semi-structured interviews with participants and by focus groups with pharmacy teams. Physical activity (measured with accelerometry at baseline, 3 and 6 months) and patient reported outcomes (activation, dietary intake and quality of life) were evaluated. Change in physical activity was used to inform the sample size calculations for a future trial.

Results Out of 403 invited men, 172 (43\%) responded and $116(29 \%)$ participated. Of these, $99(85 \%)$ completed the intervention and $88(76 \%)$ completed the 6-month follow-up (attrition 24\%). Certain components of the intervention were feasible and acceptable (eg, community pharmacy delivery), while others were more challenging (eg, fitness assessment) and will be refined for future studies. By 3 months, moderate to vigorous physical activity increased on average by $34 \mathrm{~min}(95 \% \mathrm{Cl}$ 6 to $62, p=0.018$ ), but this was not sustained over 6 months.

Conclusions The community pharmacy intervention was feasible and acceptable. Results are encouraging and warrant a definitive trial to assess the effectiveness of the refined intervention.

\section{Strengths and limitations of this study}

- This is the first study to assess the feasibility and acceptability of a community pharmacy lifestyle intervention for men living with and beyond prostate cancer.

- A mixed method design included intervention delivery data, objective accelerometry, subjective outcome measures and qualitative data that will be used to refine the intervention.

- The nine community pharmacies were drawn from three different commercial business models (independent as well as mid-size and large nationwide community pharmacy chains).

- The intervention has the potential for testing at scale because it is hosted by a web-based system used by more than 26000 different providers in the UK.

- This feasibility study did not test randomisation of participants. This will require further user involvement to explore feasibility and acceptability prior to a definitive trial.

\section{INTRODUCTION}

The number of men living with and beyond a prostate cancer diagnosis in the UK is increasing. It is predicted that by 2020 there will be over 400000 prostate cancer survivors (1.3\% of the population). ${ }^{1}$ Prostate cancer and its treatment have been shown to negatively affect men's physical ${ }^{2}$ and psychological health, ${ }^{3}$ leading to an impaired quality of life. ${ }^{4-7}$ Therefore, mitigating the consequences of cancer and its treatment is an important target for lifestyle interventions.

There is a growing body of evidence that lifestyle advice, including exercise and diet, can improve men's quality of life and symptoms related to prostate cancer or its treatment. ${ }^{8-11}$ Exercise has been shown to reduce hormone therapy-related fatigue ${ }^{12}$ and improve cardiovascular health. ${ }^{13}$ This is of 
particular importance given the potential increased risk of cardiovascular disease associated with androgen deprivation therapy (ADT) as a treatment for prostate cancer. ${ }^{14} 15$ Furthermore, an exercise programme of 12 weeks for men starting ADT is recommended by the National Institute for Health and Care Excellence (NICE) ${ }^{16}$ Lifestyle interventions also provide survivorship benefits, with increased physical activity pretreatment and post-treatment being associated with lower recurrence rates and less advanced prostate disease. ${ }^{17-19}$ The wider benefits of lifestyle interventions after cancer are improvements in metabolic health and treatment-related symptoms. ${ }^{20}$ Potential barriers to the delivery of NICE guidelines in secondary care have been well documented ${ }^{21-23}$ and include attitudes of healthcare professionals, safety concerns and issues with the hospital environment, which means that few men receive lifestyle interventions. ${ }^{21} 2425$

Primary care plays a clear and important role in supportive care during and after treatment, ${ }^{26}$ and for men with stable prostate cancer, NICE recommends hospital discharge and follow-up in primary care ${ }^{16}$ Improved access to local cancer services in the community has been advocated by the 'National Health Service (NHS) 2010-2015: from good to great' report. ${ }^{27}$ After their discharge, men have ongoing healthcare needs that require monitoring and support. ${ }^{28}{ }^{29}$ Community pharmacies are well placed to deliver this care due to easy access and availability of professional expertise. This includes consultation skills and clinical knowledge regarding management of longterm conditions and side-effects of medications including ADT. They currently deliver services such as medication use reviews, NHS Health Checks, diet and exercise advice, alcohol and smoking cessation. ${ }^{30}$ The role of community pharmacies is rapidly evolving in response to the healthcare demands of an ageing population, with multiple long-term conditions including cancer. ${ }^{31}$ Examples of health promotion and lifestyle interventions include the Healthy Living Pharmacy framework ${ }^{32}$ and NHS services such as influenza vaccination. ${ }^{33}$

The aim of this phase II study was to assess the feasibility and acceptability of a community pharmacy lifestyle intervention to improve physical activity and cardiovascular health of men with prostate cancer. This is innovative research, and to our knowledge, the first study to develop and test a lifestyle intervention in a community pharmacy setting for men living with and beyond prostate cancer diagnosis. In prostate cancer, lifestyle interventions have been shown to reduce side-effects of $\mathrm{ADT}^{101134}$ and to decrease risk of cardiovascular comorbidity. ${ }^{35}{ }^{36}$ In a feasibility study, Bourke et al showed short-term improvements in exercise and dietary behaviour due to a supervised exercise programme combined with dietary advice. ${ }^{37}$ A primary care walking programme with older adults showed improvement in step counts which resulted in health benefits. ${ }^{38}$

A novel delivery approach via community pharmacies is presented here. The study is aligned with the vision of the Royal Pharmaceutical Society of Great Britain (2017), which is for the pharmacy workforce to develop more patient-centred roles and to expand primary care services into cancer follow-ups. ${ }^{39}$ This is also advocated by the NHS and NICE. ${ }^{16} 4041$ The development and evaluation of this intervention were guided by the Medical Research Council's complex intervention framework. ${ }^{42}$ The evaluation of the feasibility and acceptability included an assessment of the delivery model (via community pharmacy), participant recruitment, consent and retention rates, and acceptability of the outcome measures. This study also provided preliminary evidence of the intervention efficacy, and enabled an assessment of the effect size change in the primary outcome to inform a future randomised controlled trial (RCT).

\section{METHODS}

\section{Setting and selection of community pharmacies}

The intervention was piloted in Portsmouth, UK home to the original Healthy Leaving Pharmacy (HLP) initiative. ${ }^{32}$ HLP provides health promotion and self-care hubs in the Portsmouth region and other areas. The health status of the population in Portsmouth falls below that of the national average, with higher deprivation and lower life expectancy (7.9 years lower for men). ${ }^{32}$ Portsmouth also provided both urban and semi-rural localities for testing the intervention.

The community pharmacy lifestyle intervention was delivered by nine community pharmacies between June 2016 and April 2017. The nine community pharmacies were recruited based on location (proximity to the cancer centre and spread across the locality) and commercial business model. They were drawn from three different commercial business models, including independent community pharmacy, mid-size nationwide community pharmacy limited company ( $>500$ pharmacies) and large nationwide pharmacy limited company ( $>1500$ pharmacies). Pharmacy teams were identified and consented to their participation in the study. This included participation in the mandatory training.

\section{Recruitment and participants}

This was a non-randomised, single-group feasibility study and all participants received the intervention. Men from the Portsmouth area, with non-metastatic prostate cancer who completed their cancer treatment a minimum of 3 months before (6months for brachytherapy) were identified from one NHS Trust. Detailed participant screening, uptake and withdrawal data were collected and analysed to assess the feasibility and acceptability of the recruitment process.

Men were invited to participate by a letter from their Consultant and asked to respond to the University of Surrey research team. Those men who contacted the research team were further screened for eligibility before discussing participation in the study. Eligibility criteria included at least one of three cardiovascular risk factors: overweight or obese (BMI 225 ), and/or on active ADT and/or diagnosed 
hypertension. Men who were already physically active were excluded because the focus of this intervention was on those with more need. The definition by the UK's Chief Medical Officer (CMO) of a minimum 150 min of moderate physical activity or a minimum of $75 \mathrm{~min}$ of vigorous physical activity per week in 10 or more minute bouts ${ }^{43}$ was used. Men, who on an initial screening, reported physical activity that exceeded CMO guidelines (eg, football, cycling or running for more than 3 hours a week) were excluded. In addition, men with an underlying medical condition that would limit their capacity to respond to advice about diet and physical activity were also excluded. All participants provided written consent. Figure 1 shows a flowchart detailing study time points and data collection activities and figure 2 the participant consort diagram.

Sample size for this feasibility study was 113 men (including an estimated $25 \%$ attrition) to detect a $22 \%$ difference in moderate to vigorous physical activity (MVPA) with $90 \%$ power, and two-tailed significance level of $5 \%$. This was informed by a lifestyle intervention conducted by Harris $e t$ $a l^{44}$ who reported a $22 \%$ (95\% CI 36 to 96) increase in weekly time in MVPA from baseline to 3 months in older adults which translated into a clinically significant improvement in cardiovascular health. ${ }^{17}$ Data clustering was not formally accounted for due to the lack of reference values. However, statistical power was increased to $90 \%$ to account for a loss in data independence. This study will be used to estimate the relatedness of data clustered at a pharmacy level, and to inform sample calculation for a definitive RCT.

\section{Intervention}

The intervention algorithm was developed in a preliminary study (phase I). It consisted of a personalised lifestyle intervention that included exercise, nutrition and psychosocial elements, guided by a functional and anthropometric personal assessment. Men received tailored home-based exercise and dietary advice with a support pack (including an educational DVD, booklet, pedometer and resistance exercise bands). Men were supported with two phone calls from a pharmacist and a follow-up appointment at 3 months after the first assessment to reassess goals, reinforce personalised lifestyle advice and support sustainability of lifestyle change. Figure 1 shows the study flow and elements of the intervention.

Training in how to deliver all aspects of the intervention was provided to pharmacy teams before the study. This consisted of existing modules from the Centre for Pharmacy Postgraduate Education (CPPE) on consultation skills and cardiovascular health, and a 1-day skills-based, competency training delivered by the research team. A team approach was adopted for the training and delivery of the intervention. Non-pharmacist members of the team delivered the assessment, and pharmacists provided the lifestyle consultation and advice. Therefore, each pharmacy nominated at least one pharmacist and at least one pharmacy technician or dispensing assistant (National Vocational Qualification level 2 or 3) to undertake the training. It was evaluated using a training evaluation form that was administered immediately after the training.

\section{Baseline data}

Participant demographic characteristics such as age, ethnicity, index of multiple deprivation (IMD), type of cancer treatment (ie, radiotherapy or surgery) and time since diagnosis, whether participants had ADT, marital and retirement statuses, family history, comorbidities and Charlson Comorbidity Index (CCI) were recorded.

\section{Primary outcome measures}

The feasibility and acceptability of the intervention and the delivery model via community pharmacy were assessed. This was by evaluating study processes (rate of participant recruitment, consent, retention and adverse events), analysing delivery data, semi-structured interviews with participants and focus groups with pharmacy teams.

\section{Secondary outcome measures}

Anthropometrics that define cardiovascular risk, such as weight, body mass index (BMI), waist circumference, blood cholesterol and blood pressure were assessed. In addition, upper-limb (grip strength ${ }^{45}$ ) and lower-limb (chair sit-to-stand ${ }^{46}$ ) tests were administered to classify men into low, medium and high strength groups (using age-specific cut-offs). Functional fitness was assessed with the Siconolfi step test ${ }^{47}$ to inform classification into low, medium and high groups of fitness. Self-reported physical activity was also assessed by Godin leisure-time exercise questionnaire (GLTEQ).$^{48}$ These outcomes were measured at both pharmacy visits.

Objective assessments of physical activity were performed with wrist-worn accelerometers (ActiWatch V.4.0) and used to calculate weekly time spent in MVPA at baseline, 3 months and 6 months, independent of the pharmacy assessments. Study participants received the device by post and were instructed to wear the ActiWatch continuously for 7 days, removing it only to avoid exposure to water. Valid data were defined as at least 1 day of wear time. ${ }^{44}$ Accelerometry estimates physical activity levels by using short time sampling intervals (epochs). Standard 30 seconds epochs were used to collect the physical activity data and rescaled to 60 seconds epochs to obtain counts per minute (CPM). CPM were used in data analysis to calculate time spent weekly in MVPA (cutoff $\geq 1041$ CPM.) ${ }^{49}$ Change in MVPA was used to inform the sample size calculations for a future RCT.

Patient reported data were also collected. This included dietary intake with the Mediterranean Diet Adherence Screener (MEDAS) questionnaire ${ }^{50}$ Patient Activation Measure (PAM) ${ }^{51}$ prostate cancer-related symptoms with the Expanded Prostate Cancer Index Composite (EPIC26) tool $^{52}$ and quality of life with the EQ5D-5L questionnaire. ${ }^{53}$ These data are to be reported in a subsequent paper. They were administered via postal questionnaires at baseline, 3 months (only MEDAS and PAM) and at 6 months (study flowchart in figure 1). 


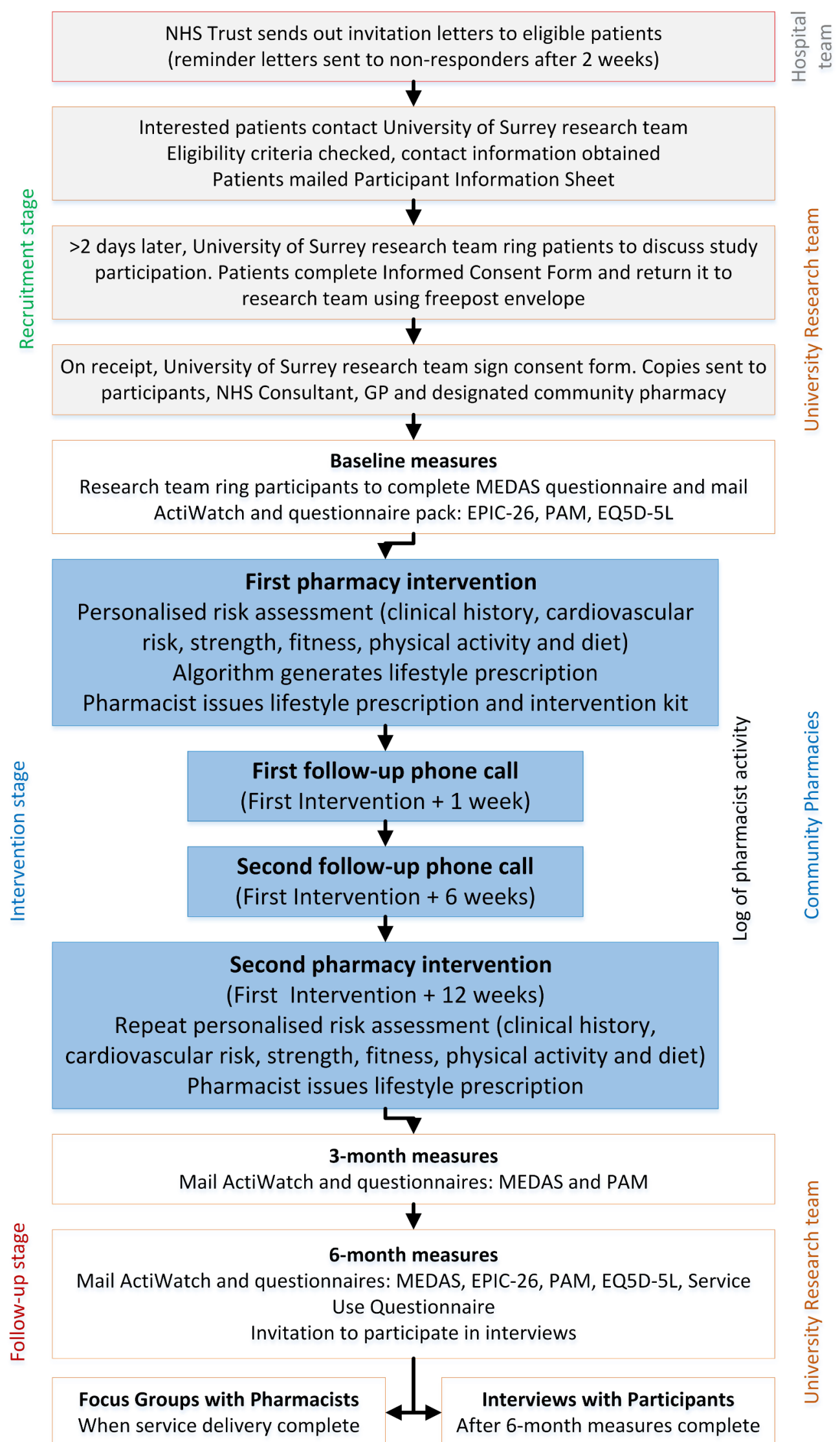

Figure 1 Study flowchart indicating recruitment and intervention components and time points. BP, blood pressure; EPIC, Expanded Prostate Cancer Index Composite; EQ5D-5L, EuroQol 5 dimensions 5 levels; GP, general practitioner; MEDAS, Mediterranean Diet Adherence Screener; NHS, National Health Service; PAM, Patient Activation Measure. 
Assessed for eligibility ( $n=1173)$

\begin{tabular}{|c|c|}
\hline$\downarrow$ & $\begin{array}{c}\text { Excluded }(\mathbf{n}=\mathbf{7 7 0}) \\
\text { reasons: did not meet inclusion criteria }(n=761) \text {, } \\
\text { letters not sent }(n=9)\end{array}$ \\
\hline Responded $(n=172)$ & $\begin{array}{c}\text { Excluded ( } n=37) \\
\text { reasons: did not meet inclusion criteria }(n=37) \\
\text { Declined }(n=10) \\
\text { reasons: 'feel too fit to benefit' }(n=3) \text {, 'too much } \\
\text { going on' ( } n=6) \text {, 'unable to go to preferred } \\
\text { pharmacy' }(n=1)\end{array}$ \\
\hline Consented $(n=125)$ & $\begin{array}{l}\text { Withdrawn }(\mathrm{n}=4) \\
\text { reasons: 'too much going on' }(n=2) \text {, 'relocation for } \\
\text { new job' }(n=1) \text {, 'preferred pharmacy not available' } \\
(n=1)\end{array}$ \\
\hline $\begin{array}{c}\text { Baseline evaluation }(n=121) \\
\text { AW data }(n=116)(\text { invalid AW data } n=5) \\
\text { Questionnaire data }(n=118)(\text { missing } n=3)\end{array}$ & $\begin{array}{l}\text { Withdrawn }(\mathrm{n}=5) \\
\text { reasons: 'too much going on' }(n=1) \text {, 'unwell' }(n=1) \text {, } \\
\text { 'preferred pharmacy not available' }(n=1) \text {, } \\
\text { 'appointment too late' }(n=1) \text {, 'repeated } D_{N A}(n=1)\end{array}$ \\
\hline $\begin{array}{l}\text { Completed second community pharmacy } \\
\text { appointment }(n=99)^{*}\end{array}$ & $\begin{array}{c}\text { Withdrawn }(n=10) \\
\text { reasons: 'unwell' }(n=6) \text {, 'wife unwell' }(n=1) \text {, } \\
\text { 'dissatisfied' }(n=1) \text {, 'other commitments' }(n=2) \\
\text { Assessment suspended }(n=1) \\
\text { reason: } B P \text { too high to proceed } \\
\text { Declined }(n=6) \\
\text { reasons: 'forgot to attend appointment' }(n=4) \text {, } \\
\text { 'pharmacy failed to book' ( } n=1) \text {, 'attended but } \\
\text { preferred not to complete assessment' }(n=1)\end{array}$ \\
\hline $\begin{array}{l}\text { 3-month evaluation }(n=105) \\
\text { AW data }(n=88) \text { (invalid AW data } n=6 \text {, } \\
\text { declined } n=10 \text {, lost in post } n=1 \text { ) }\end{array}$ & $\begin{array}{l}\text { Withdrawn }(\mathrm{n}=1) \\
\text { reason: 'unwell' }\end{array}$ \\
\hline & $\begin{array}{c}\text { Withdrawn ( } \mathbf{n}=\mathbf{2}) \\
\text { reason: 'not keen to repeat questionnaires and } \\
A W^{\prime}\end{array}$ \\
\hline
\end{tabular}

6-month evaluation $(n=103)$

AW data $(n=88)$ (invalid AW data $n=2$,

declined $n=5$, lost in post $n=8$ )

Questionnaire data $(n=92)$ (missing $n=11)$

Semi-structured interviews $(n=33)$

*Some men did not attend the second Community Pharmacy Appointment, but continued to provide evaluation data

Figure 2 Consort diagram demonstrating recruitment and retention of participants throughout the study.

\section{Process data}

Information on any logistic or technical problems during the study were recorded, as for example, problems scheduling assessments or technical problems with equipment, web-based system or computer algorithm. The duration of each consultation was automatically recorded by the system. Service evaluation data were also captured by participants.

\section{Qualitative data}

Two focus groups were held with the participating pharmacy teams at the end of the project to collect information on the feasibility and acceptability of intervention components and to obtain feedback on their preparatory training. This provided an opportunity to discuss experiences as a group of healthcare professionals across pharmacy teams. Semi-structured interviews with a consecutive sample of study participants were also conducted to collect the information on their overall perception and engagement with different intervention components. Six months after enrolment, 44 of the 116 participants were consecutively approached to take part in an interview. Of these, five men declined without providing a reason and three declined due to the timing of the interviews. Thirty-six men gave written consent and 33 men were interviewed (in three cases, it was not possible to find a mutually convenient time). The focus groups and interviews were audio-recorded, transcribed and analysed thematically. 


\section{Quantitative data}

Baseline patient characteristics and changes over time were analysed using descriptive statistics. Means and SD were used for normally distributed variables. Medians and 25th and 75th percentiles were used for non-normally distributed variables. Frequencies and percentages were used for categorical variables. The significance of standardised mean differences from baseline to 3 months in normally distributed continuous outcome measures was calculated with $95 \%$ CIs. The proposed primary outcome measure for a future RCT was the change from baseline to 3 months in weekly MVPA. The effect size change in this outcome was used to estimate sample size. An intracluster correlation coefficient (ICC) was calculated to account for the relatedness of data clustered at a pharmacy level. ${ }^{54}$

Multilevel logistic regression was used to examine the relationship between potential factors influencing change in MVPA over 3 months. A binary (yes/no) variable of increase in MVPA was used as a dependent variable. Pharmacy effect was included as a random variable. Univariate models were fitted with the following independent variables: baseline time in MVPA, age, BMI status, cancer treatment, ADT, marital status, IMD decile and CCI score. The final multivariate model was created using a backward elimination procedure and statistical significance of $\mathrm{p}<0.1$ as cut-off. Collinearity between independent variables was tested using Spearman's rank correlation coefficient $r . \mathrm{P}<0.05$ was considered statistically significant. The data set was entered and managed in SPSS V.22. Statistical analyses were performed in R V.3.0.2.

\section{Missing data and data processing}

Statistical analyses were performed on all 116 study participants who commenced the pharmacy intervention, on an intention to treat basis as recommended by the Consolidated Standards of Reporting Trials guidelines. ${ }^{55}$ Missing data were imputed for 17 men who did not attend the second pharmacy visit, 28 who failed to provide 3-month ActiWatch follow-up data, and 28 men who failed to provide 6-month ActiWatch data, using the method of last observation carried forward (LOCF). ${ }^{56} 57$ Data were imputed to preserve sample size and to prevent attrition bias. The predictable and conservative approach of LOCF was preferred over multiple imputation because this minimises the risk of overestimation of results (the effect of lifestyle intervention) due to data imputation. ${ }^{59}$ A sensitivity analysis by complete case analysis produced similar results.

\section{Patient and public involvement}

Men with prostate cancer were actively involved in the design and implementation of this feasibility study. Two volunteers, who are prostate cancer survivors, were involved in the codesign of the intervention resources, training of the community pharmacy teams and supported project management and governance. The study results were shared and consulted with the study participants and their families via a feedback event organised at the end of the study.

\section{RESULTS}

\section{Recruitment and retention}

In total, 1173 health records of men with prostate cancer were screened and assessed for suitability, based on inclusion criteria and geographic proximity to participating pharmacies. Study invitation letters were sent to 403 men, and $172(43 \%)$ expressed interest in taking part. Of these, 37 did not meet the inclusion criteria and 10 declined; 125 men returned signed consent forms, but nine withdrew before they commenced the pharmacy intervention (consort diagram in figure 2).

A sample of 116 men commenced the lifestyle intervention. This constituted the main study cohort for all data analyses. This cohort had a mean age $70.4 \pm 7.2$ years (range 50-85), of which 99 men completed the 3-month pharmacy intervention (15\% withdrawn), 88 returned their 3-month ActiWatch data and 88 provided their 6-month ActiWatch data (24\% attrition rate) (figure 2 ).

\section{Feasibility and acceptability of the intervention and delivery model}

The first pharmacy assessments were delivered from June 2016 to November 2016. The second pharmacy assessments were delivered between September 2016 and April 2017. The median time between consultations was 15 weeks. Community pharmacies were easy to access for men and the pharmacy teams had the skills and confidence to complete the training and deliver the intervention. The community pharmacy delivery was feasible for the providers and acceptable to men with prostate cancer. This is reflected by the relatively small $(15 \%)$ attrition of participants from the pharmacy intervention. In addition, $86 \%$ of men received 1-week telephone follow-ups and $71 \%$ received 6-week telephone follow-ups. The number of consultations per pharmacy varied between 4 to 30 for the first assessment and 4 to 32 for the second assessment. This was primarily driven by the choice of participants and usually determined by the ease of access or proximity of a pharmacy. Due to staff changes and workload, some participants moved to another pharmacy to complete their follow-up. Pharmacists could pick-up those appointments and the web-based system enabled this transfer.

\section{Feasibility and acceptability of outcome measures}

At baseline, the average weight was $86.9 \pm 14.0 \mathrm{~kg}$ and 91 $(78 \%)$ men were overweight or obese using BMI (table 1). The average grip strength was $35.7 \pm 6.7 \mathrm{~kg}$ and $69(60 \%)$ men were classified as having low upper-limb strength. The median number of chair sit-to-stands was 13 (IQR was $10-15)$ and $55(47 \%)$ men were classified as having low lower-limb strength. Using the Siconolfi step test 49 (42\%), $38(33 \%)$ and $29(25 \%)$ men were classified as having low, moderate and high fitness levels, respectively.

At the second pharmacy visit, upper-limb strength increased on average by $0.2 \pm 3.0 \mathrm{~kg}(\mathrm{p}=0.393)$ and lowerlimb strength also increased significantly. Median difference (IQR) was $1(0-3)$ chair sit-to-stands $(\mathrm{p}<0.001)$. Physical fitness did not change significantly $(\mathrm{p}=0.339)$. QRisk2 fell 
Table 1 Baseline demographic and anthropometric characteristics of the study population $(n=116)$

\begin{tabular}{|c|c|c|c|}
\hline & Mean (SD) & $\begin{array}{l}\text { Median (Q1, } \\
\text { Q3) }\end{array}$ & n (\%) \\
\hline Age (years) & $70.4(7.2)$ & $71(65,76)$ & \\
\hline$<60$ & & & $9(8)$ \\
\hline $60-69$ & & & $40(35)$ \\
\hline $70-79$ & & & $56(48)$ \\
\hline$\geq 80$ & & & $11(10)$ \\
\hline Ethnicity (white) & & & $114(98)$ \\
\hline Marital status (married/partner) & & & $102(88)$ \\
\hline Retirement (retired) & & & $89(77)$ \\
\hline Smoking status (current smoker) & & & $2(2)$ \\
\hline IMD & & $7.5(5,9)$ & \\
\hline 1-3 (most deprived) & & & $16(14)$ \\
\hline $4-6$ & & & $24(21)$ \\
\hline $7-8$ & & & $37(32)$ \\
\hline 9-10 (least deprived) & & & $39(34)$ \\
\hline $\mathrm{CCl}$ & & $2(2,3)$ & \\
\hline$\leq 2$ (mild) & & & $84(72)$ \\
\hline 3-4 (moderate) & & & $16(28)$ \\
\hline$\geq 5$ (severe) & & & $0(0)$ \\
\hline $\mathrm{CCl}$ age adjusted score & & $6(5,6)$ & \\
\hline PAM score & & $3(2,3)$ & \\
\hline Level 1 (lowest) & & & $15(13)$ \\
\hline Level 2 & & & $16(14)$ \\
\hline Level 3 & & & $58(50)$ \\
\hline Level 4 (highest) & & & $25(22)$ \\
\hline Missing & & & $2(2)$ \\
\hline Time since diagnosis (years) & $1.5(0.7)$ & & \\
\hline$\leq 1$ & & & $72(62)$ \\
\hline$>1$ & & & $36(31)$ \\
\hline Missing & & & $8(7)$ \\
\hline \multicolumn{4}{|l|}{ Treatment } \\
\hline Surgery & & & $49(42)$ \\
\hline Radiotherapy & & & $69(60)$ \\
\hline Brachytherapy & & & $4(4)$ \\
\hline ADT & & & $66(57)$ \\
\hline
\end{tabular}

Number of participants per pharmacy

\begin{tabular}{ll} 
A & $21(18)$ \\
\hline B1 & $9(8)$ \\
B2 & $8(7)$ \\
\hline B3 & $9(8)$ \\
\hline B4 & $18(16)$ \\
\hline C1 & $30(26)$ \\
\hline C2 & $8(7)$ \\
C3 & $4(3)$ \\
C4 & $9(8)$ \\
\hline
\end{tabular}

Anthropometrics

\begin{tabular}{lcc} 
Weight $(\mathrm{kg})$ & $86.9(14.0)$ & \\
$\mathrm{BMI}\left(\mathrm{kg} / \mathrm{m}^{2}\right)$ & $28.1(4.1)$ & \\
$\mathrm{BMI} \geq 25 \mathrm{~kg} / \mathrm{m}^{2}$ (overweight/obese) & & Continued \\
\hline
\end{tabular}

Table 1 Continued

\begin{tabular}{|c|c|c|c|}
\hline & Mean (SD) & $\begin{array}{l}\text { Median (Q1, } \\
\text { Q3) }\end{array}$ & n (\%) \\
\hline Waist circumference (cm) & $102.8(11.0)$ & & \\
\hline $\begin{array}{l}\text { Obese, waist } \\
\text { circumference } \geq 102 \mathrm{~cm}\end{array}$ & & & $63(54)$ \\
\hline Waist-to-hip ratio & $0.97(0.06)$ & & \\
\hline Waist-to-hip ratio $>0.90$ (obese) & & & $101(87)$ \\
\hline Total cholesterol (mmol/L) & $4.7(1.3)$ & & \\
\hline Cholesterol ratio & $4.0(1.3)$ & & \\
\hline Systolic blood pressure $(\mathrm{mm} \mathrm{Hg})$ & $134(16)$ & & \\
\hline Diastolic blood pressure $(\mathrm{mm} \mathrm{Hg})$ & $81(11)$ & & \\
\hline \multicolumn{4}{|l|}{ Cardiovascular health } \\
\hline QRisk2 & $25.6(11.3)$ & & \\
\hline QRisk2 $\geq 20$ (high risk) & & & $83(72)$ \\
\hline \multicolumn{4}{|l|}{ Accelerometry data } \\
\hline Counts per day (1000 counts) & $271(100)$ & & \\
\hline MVPA per week (min) & $245(250)$ & & \\
\hline $\begin{array}{l}\text { MVPA per week in } \geq 10 \text { min bouts } \\
\text { (min) }\end{array}$ & $31(67)$ & & \\
\hline Achieving $\mathrm{CMO}$ guidance (N, \%) & & & $8(7 \%)$ \\
\hline \multicolumn{4}{|l|}{ Fitness and strength } \\
\hline $\begin{array}{l}\text { Upper-limb strength (grip strength) } \\
\text { (kg) }\end{array}$ & $35.7(6.7)$ & & \\
\hline Low & & & $69(59)$ \\
\hline Moderate & & & $22(19)$ \\
\hline High & & & $25(22)$ \\
\hline $\begin{array}{l}\text { Lower-limb strength (sit-to-stands } \\
\text { in } 30 \text { seconds) }\end{array}$ & & $13(10,15)$ & \\
\hline Low & & & $55(47)$ \\
\hline Moderate & & & $48(41)$ \\
\hline High & & & $13(11)$ \\
\hline \multicolumn{4}{|l|}{ Physical fitness (Siconolfi step test) } \\
\hline Low & & & $49-42$ \\
\hline Moderate & & & $38-33$ \\
\hline High & & & $29-25$ \\
\hline
\end{tabular}

$\mathrm{ADT}$, androgen deprivation therapy; $\mathrm{BMI}$, body mass index; $\mathrm{CCl}$, Charlson comorbidity index; CMO, chief medical office; IMD, index of multiple deprivation; MVPA, moderate to vigorous physical activity; PAM, patient activation measure; Q1, 25th percentile; Q3, 75th percentile; QRisk2, QRisk2 2017 cardiovascular disease risk calculator (qrisk.org/2017).

significantly by $1.5 \%(\mathrm{p}<0.001)$. The reduction in weight by $1.0 \mathrm{~kg}(\mathrm{p}<0.001)$, BMI by $0.3 \mathrm{~kg} / \mathrm{m}^{3}(\mathrm{p}<0.001)$, total cholesterol by $0.4 \mathrm{mmol} / \mathrm{L}(\mathrm{p}=0.004)$ and cholesterol ratio by 0.5 $(\mathrm{p}<0.001)$ contributed to this result (online supplementary appendix table A1).

The three physical assessment tests (upper-limb, lowerlimb strengths and fitness) were generally acceptable and feasible. At baseline, one man did not attempt the sit-tostand test and 13 did not attempt the Siconolfi step test. At 3 months, it was six and 22 men, respectively. The reasons for not participating included injuries, increased heart rate, dizziness, not willing to participate or technical problems with equipment. Siconolfi step test was used to assess men's physical fitness and those who attempted it, often found it 
Table 2 Results of multilevel logistic regression using binary (yes/no) variable of increase in MVPA as a dependent variable

\section{Dependant variable}

Increase in MVPA (yes/no)

Yes $(\mathrm{n}=62)$

No $(n=54)$ (reference)

\begin{tabular}{|c|c|c|c|c|c|c|c|c|}
\hline \multirow[t]{2}{*}{ Independent variables (fixed effects) } & \multicolumn{3}{|c|}{ Univariate model } & \multicolumn{5}{|c|}{ Multivariate model } \\
\hline & Estimate & Error & P value & Estimate & Error & P value & $2.5 \% \mathrm{Cl}$ & $97.5 \% \mathrm{Cl}$ \\
\hline Time in MVPA (100 min) & -0.22 & 0.09 & 0.018 & -0.28 & 0.12 & 0.014 & -0.529 & -0.077 \\
\hline BMI status: normal & Reference & & & & & & & \\
\hline BMI status: overweight & -0.34 & 0.49 & 0.494 & -0.87 & 0.56 & 0.125 & -2.030 & 0.203 \\
\hline Cancer treatment: radiotherapy & Reference & & & & & & & \\
\hline Cancer treatment: surgery & -0.74 & 0.38 & 0.052 & -0.77 & 0.42 & 0.067 & -1.618 & -0.045 \\
\hline ADT: no & Reference & & & & & & & \\
\hline ADT: yes & 0.38 & 0.38 & 0.307 & & & & & \\
\hline Employment status: working & -0.47 & 0.44 & 0.286 & & & & & \\
\hline IMD decile: 1-3 (most deprived) & Reference & & & & & & & \\
\hline IMD decile: 4-6 & -0.25 & 0.65 & 0.698 & & & & & \\
\hline IMD decile: 7-8 & 0.02 & 0.60 & 0.973 & & & & & \\
\hline IMD decile: 9-10 (least deprived) & -0.20 & 0.60 & 0.738 & & & & & \\
\hline CCl score: mild & Reference & & & & & & & \\
\hline CCI score: moderate & -0.02 & 0.41 & 0.966 & & & & & \\
\hline
\end{tabular}

Pharmacy (clustering effect) was included as a random effect. Factors that can potentially contribute to the change in MVPA over time were explored using univariate regression. The following independent variables were included: baseline time in MVPA (continuous), age (continuous), BMI status (categorical; normal, overweight, obese), cancer treatment (categorical; radiotherapy, surgery), ADT (categorical; yes, no), marital status (categorical; single, partner), employment status (categorical, unemployed/retired, working), IMD decile (categorical; 1-3, $4-6,7-8,9-10$ ) and CCI score (categorical; mild, moderate, severe). A backward elimination procedure and statistical significance of $p<0.1$ was used to derive a final multivariate model. $\mathrm{P}<0.05$ was considered statistically significant. ADT, androgen deprivation therapy; BMI, body mass index; $\mathrm{CCl}$, Charlson Comorbidity Index; IMD, index of multiple deprivation; MVPA, moderate to vigorous physical activity.

a useful 'reality check' that motivated them to make lifestyle changes. However, the length of the test and the issues related to the small size of consultation room ('step test too close to the wall' or 'too hot') were identified as challenges for the delivery of the step test in this setting.

Assessing MVPA using accelerometry was feasible and acceptable to the participants. At baseline, 111 (96\%) men provided valid ActiWatch data. The dropout rate at three and 6 months was 28 participants $(24 \%)$. The change in MVPA from baseline to 3 months was the proposed main outcome for future evaluations of the effectiveness of the intervention. At baseline, men spent on average $245 \pm 250 \mathrm{~min}$ in MVPA per week. This increased significantly by $34 \pm 152 \mathrm{~min}(\mathrm{p}=0.018)$ at 3 months. The statistical significance of the change was not sustained at 6 months and the average increase from baseline was $14 \pm 220 \mathrm{~min}$ $(p=0.509)$. When counting time in bouts of $\geq 10 \mathrm{~min}$ (as recommended by the CMO guidance),${ }^{43}$ only eight men
(7\%) achieved the recommended minimum of $150 \mathrm{~min}$ in MVPA per week. The standardised mean changes in MVPA and other outcome measures from baseline to 3 months are presented in figure 3 .

\section{Adverse events}

There were no falls or injuries reported as a direct result of any of the research procedures. Three participants were stopped from performing the Siconolfi step test for safety reasons because they reported dizziness during the pre-assessment with the physical activity readiness questionnaire. ${ }^{60}$ A further 15 participants were stopped from participating in the Siconolfi step test because their heart rate or blood pressure was above the recommended safety limits $(85 \%$ of the age-predicted maximum heart rate, $160 \mathrm{~mm} \mathrm{Hg}$ systolic or $110 \mathrm{~mm} \mathrm{Hg}$ diastolic blood pressure). They were referred to their general practitioners and no exercise advice was provided. 


\section{Outcome measure}

- significant and favourable change

- non-significant change

0.394

Upper body strength

Time in MVPA (min)

QRisk2

Diastolic BP (mm Hg)

Systolic BP (mm Hg)

Glucose (mmol/L)

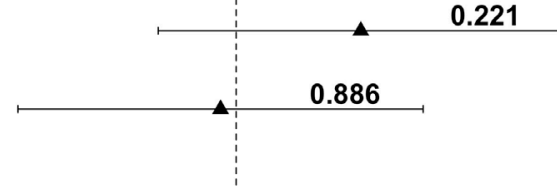

Cholesterol ratio

Total cholesterol ( $\mathrm{mmol} / \mathrm{L})$

Waist to hip ratio

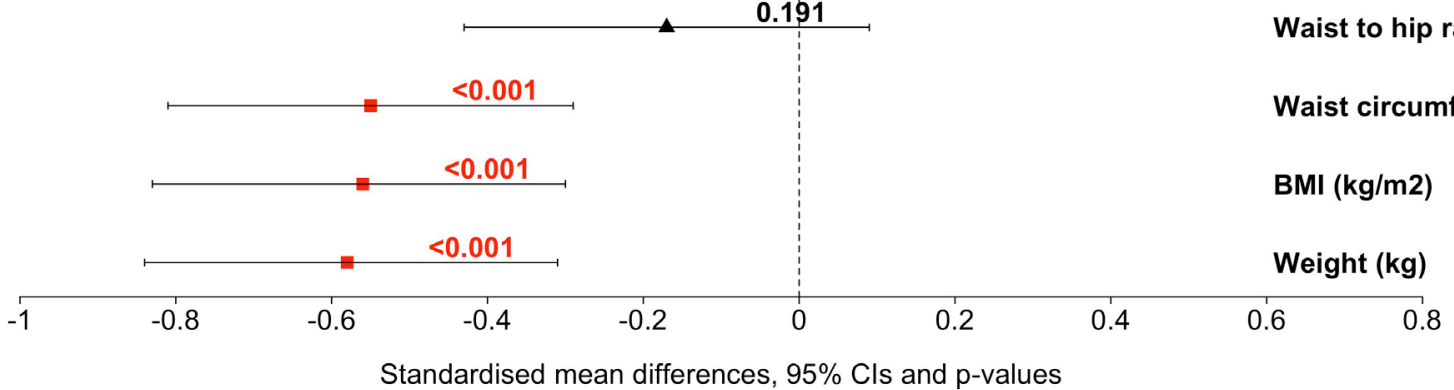

Figure 3 Standardised mean changes in outcome measures from baseline to 3 months. All significant changes are in a favourable direction and are marked in red. BMI, body mass index; BP, blood pressure; MVPA, moderate to vigorous physical activity; QRisk2, QRisk2 2017 cardiovascular disease risk calculator (qrisk.org/2017).

\section{Factors that influence change in physical activity}

Age did not influence the change in MVPA from baseline to 3 months $(p=0.548)$ (table 2$)$. The main predictors of increase in MVPA were the baseline time in MVPA $(\mathrm{p}=0.027)$ and the BMI status $(\mathrm{p}=0.008)$. The increase in MVPA was inversely associated with the amount of MVPA at baseline, so the more MVPA men did at baseline, the less likely it was to improve at 3 months. In addition, obese men were less likely to increase their MVPA than men with normal BMI.

\section{Sample size for a future RCT}

The change in weekly time spent in MVPA from baseline to 3 months is the proposed primary outcome used for the calculation of sample size. The ICC for the change in MVPA from baseline to 3 months was 0.04 (95\% CI -0.03 to 0.28 ) and the effect size for paired data was estimated as 0.22 (95\% CI -0.04 to 0.48$)$, which by thresholds defined by Jacob ${ }^{61}$ represented a small effect size. To achieve $80 \%$ power at a two-tailed significance level of 0.05 , a sample size of 632 men would be required to demonstrate the effectiveness of this lifestyle intervention at 3 months in a future RCT. Further adjustment for the loss of statistical power due to a clustering of data, ${ }^{54}$ and allowance for an estimated $25 \%$ attrition, increases this to 1202 men.

\section{DISCUSSION}

Feasibility and acceptability of the intervention

This is the first study to test the feasibility and acceptability of a community pharmacy lifestyle intervention for men with prostate cancer in preparation for an RCT. Overall, the design was found to be feasible and the intervention acceptable to both providers and men living beyond a diagnosis of prostate cancer.

The results of this study confirm that a community pharmacy lifestyle intervention is acceptable to men living with and beyond cancer. The study also demonstrates that it is feasible to deliver the intervention in three different commercial community pharmacy models. A strength of the recruitment strategy was that the invitation letters were sent via oncology consultants. There is evidence that physician-prompting improves recruitment to clinical trials. ${ }^{62} 63$ In addition, studies show that individuals participate in clinical research for altruistic reasons. ${ }^{64}$ Men who participated were not only keen to improve their health and fitness, but also keen to contribute towards improving future support for other men after treatment. The main reasons for non-participation were too busy, unwell or already physically active. This increased understanding of facilitators and barriers to participation will be used in the planning of a successful recruitment strategy for a future trial. 
Given that prostate cancer survivorship is frequently accompanied by comorbid conditions and an increased risk of cardio-metabolic disease, ${ }^{14}{ }^{15}$ community-based provision of lifestyle advice could have far-reaching implications for future health and quality of life in this patient group. However, the effectiveness of this model may depend on better communication between primary and secondary care. Qualitative data from participant interviews and focus groups with pharmacy teams revealed that the participants wrongly assumed that pharmacists had access to their NHS hospital and primary care records. A number of challenges due to the poor information exchange between primary and secondary sectors have been identified in the literature, ${ }^{65}$ suggesting a limited ability to provide a continuum of care and lack of a coordinated approach to managing comorbidities. Patients often report unmet information and support needs during and after treatment. ${ }^{66} 67$ This community pharmacy model could be used as a platform for reducing unmet health needs and in ensuring a more seamless transition from oncology services to primary care support during and beyond prostate cancer treatment.

\section{Informing a design of a definitive RCT}

The potential benefits of lifestyle interventions in prostate cancer survivors include decreased disease recurrence and improvements in quality of life, fatigue and physical function. ${ }^{68}$ However, a systematic review of exercise interventions has shown that it is unrealistic for the majority of older sedentary men in UK to achieve the exercise levels recommended by the CMO guidelines. ${ }^{69}$ This was also true in our study where only $7 \%$ of men achieved it. While this study provides evidence of the potential to improve physical activity and reduce health risks of men with prostate cancer, there needs to be more consideration of how to sustain lifestyle changes long term. In our study, the increase in physical activity at 6 months, fell from the statistically significant increase level at 3 months.

The $7 \%$ of men achieving CMO guidelines, reported here, was lower than the $12 \%$ reported for cancer patients in Galvao et $a l^{70}$ and lower than the $38 \%$ reported for older adults in UK population. ${ }^{71}$ This may be due to the recruitment bias resulting from targeting men with low physical activity levels and pre-existing cardiovascular risk factors, including obesity. Men with higher MVPA levels at baseline showed no improvement in MVPA over the course of the study. In addition, obesity was identified as a barrier to increasing MVPA. Although these men were not achieving recommended MVPA levels, they were potentially able to increase physical activity, for example via the leisure-time exercise (such as walking or gardening). This still provides health benefits but may not be captured by accelerometery and therefore under-reported in the MVPA outcome. Age-specific accelerometer cut-offs have been devised by Rejeski $e t a l^{72}$ and should be used to increase the sensitivity of physical activity intensity classifications, personalised advice and to improve the potential for capturing clinically meaningful improvements.
In this respect, the extent to which current CMO physical activity guidelines are appropriate for older prostate cancer patients is unknown. They may be unrealistic in terms of what older or obese cancer survivors can achieve. We therefore suggest, that lifestyle advice should be tailored to age, weight and individual capabilities, including the setting of realistic goals, ${ }^{73}$ with the ultimate aim of achieving (or exceeding) CMO recommendations. Overweight and obese men were a significant proportion $(78 \%)$ of the sample and they were less likely to improve their MVPA. They may potentially benefit from a tailored or stepped approach to weight loss during or prior the exercise intervention. In addition, the results show that the significant increase in MVPA at 3 months was not sustained over 6 months. Therefore, to maintain adherence and realise long-term benefits, it would be beneficial to consider how maintenance can be enhanced through behavioural change techniques for future evaluations of this intervention.

\section{Strengths and limitations}

The recruitment approach was a clear strength of this study. The results demonstrate that an invitation from an oncology consultant is helpful in promoting interest in lifestyle intervention research. Another strength was that participating pharmacies were drawn from different business models, ensuring that the findings are representative across the sector. The intervention effect size and pharmacy clustering effect were calculated and this can be used to estimate the sample size for a future RCT. This is a strength, because to our knowledge there is no other research to provide this information. While the intervention was limited to one geographic location, the individual pharmacies were selected to provide socioeconomic diversity and mixture of urban and semi-rural settings that were representative of a wider area.

The intervention was built on a web-based platform that is used each year by more than $87 \%$ of the 11700 community pharmacies in England, and more than 26000 different providers in the UK. This was to ensure that the intervention would be flexible with regard to a geographic location and that it was feasible to rapidly scale-up. The use of accelerometery for the proposed primary outcome measure is a strength because it provides an objective evaluation of physical activity. Information about frequency, intensity and duration (time) of exercise can be obtained. However, accelerometery provides limited information, in particular about the type of physical activity. This is important to consider in light of the frequency, intensity, time and type (FITT) principle. ${ }^{74}$ With an older population, individuals often get exercise via activities of daily living or leisure (eg, walking or gardening). Therefore, to explore the adherence to exercise interventions, the objective measures such as accelerometery should not be used alone. Here, leisuretime physical activity was assessed using the self-reported GLTEQ. Upper-limb and lower-limb strengths were also 
assessed to objectively capture the potential changes due to the prescribed resistance training.

In addition, analysis of men's perceptions and adherence to the intervention were also conducted using qualitative interviews. This was to capture the utilisation of resistance exercise bands and adherence to the strength training element of the intervention. This is important for the functional strength of men but is not captured by accelerometery. An original version of the validated GLTEQ $^{48}$ was used in this study. It is a tool used internationally in oncology research to evaluate exercise interventions or assess a relative change in total exercise behaviour. ${ }^{75}$ However, item content of the GLTEQ may lead to under-reporting of resistance training activities, such as those using resistance bands. Adapted GLTEQ versions designed to capture the resistance training have been reported. ${ }^{76} 77$

This feasibility study did not test randomisation of participants. This was guided by a requirement from the funder that the intervention was provided to all participants. This is a limitation and will require further user involvement and consultations to explore feasibility and acceptability prior to a future RCT. The lack of ethnic variability is a limitation. The majority of our sample are white men, so we did not explore ethnic differences in feasibility and acceptability. To remedy this in a future trial, recruitment needs to take place in areas with higher rates of ethnic minorities.

\section{CONCLUSIONS}

This study shows that community pharmacies could have an important role in supporting cancer survivorship initiatives in primary care, providing accessible, personalised lifestyle interventions in the high street. New evidence is provided for the potential of pharmacy-led lifestyle interventions to benefit the health of men living with and beyond prostate cancer. The algorithm and the fitness assessment require further refinement to be more practical in the pharmacy setting. However, the preliminary results are promising. Men were shown to improve physical activity, other lifestyle factors, and cardiovascular risk score. They may need more support to maintain such benefits in the long-term. This study is an essential step towards an RCT to evaluate the effectiveness and cost-effectiveness of this community pharmacy lifestyle intervention for men with prostate cancer.

\section{Author affiliations}

${ }^{1}$ School of Health Sciences, Faculty of Health and Medical Sciences, University of Surrey, Guildford, UK

${ }^{2}$ Department of Nutritional Sciences, Faculty of Health and Medical Sciences,

University of Surrey, Guildford, UK

${ }^{3}$ School of Biosciences and Medicine, Faculty of Health and Medical Sciences, University of Surrey, Guildford, UK

${ }^{4}$ Department of Sport, Exercise and Rehabilitation, Northumbria University, Newcastle upon Tyne, UK

${ }^{5}$ Frimley Health NHS Foundation Trust, Frimley, UK

${ }^{6}$ Surrey Human Performance Institute, University of Surrey, Guildford, UK
Acknowledgements We thank men and their families for their participation and contribution to the project. We thank clinicians at the Portsmouth Hospitals NHS Trust for their help recruiting participants and Lloyds Pharmacy Ltd, Rowlands Pharmacy Ltd and City Pharmacy organisations and staff for participating in the study. We thank all members of the Study Advisory Committee for their contribution and their advisory role on the project: John Heyworth and John Marshall, Patient and Public Involvement, Prostate Cancer UK; Sally Greensmith, Centre for Pharmacy Postgraduate Education, University of Manchester; Zachariah Nazar, University of Portsmouth; Graham Phillips, Manor Pharmacy Group, Herts; Gary Warner and Kevin Noble, PharmOutcomes, Pinnacle Health Partnership LLP. Fiona Archer and Sophie Gasson are thanked for leading data collection and data entry aspects.

Contributors AL, KP and SF drafted most of this manuscript. All authors contributed to the manuscript, data analysis and interpretation. SF was Principal Investigator. AL coordinated engagement with community pharmacies, implemented the web-based algorithm and was a lead author. KP was the project manager and coordinated ethical approvals. JS, RM and JW supported the project with expertise in exercise physiology. BG and LT provided expertise in nutrition.

Funding This study (NIHR/UKCRN ID 20874) was funded by the Movember Foundation, in partnership with Prostate Cancer UK, as part of the global True NTH programme, grant number 250-20 and was supported by the NIHR Clinical Research Network.

Competing interests SF is a trustee of Prostate Cancer UK. All other authors declare that they have no competing interests.

Patient consent for publication Obtained.

Ethics approval The NHS Health Research Authority South Central-Berkshire B Research Ethics Committee gave a favourable ethical opinion for this study (16/ $\mathrm{SC} / 0069)$. Research governance assurance was provided by Wessex Primary Care Research Support Service (IRAS ID 193263, 4 April 2016) and permission gained from each community pharmacy contractor hosting the study.

Provenance and peer review Not commissioned; externally peer reviewed. Data sharing statement Data from this study are available on request.

Open access This is an open access article distributed in accordance with the Creative Commons Attribution Non Commercial (CC BY-NC 4.0) license, which permits others to distribute, remix, adapt, build upon this work non-commercially, and license their derivative works on different terms, provided the original work is properly cited, appropriate credit is given, any changes made indicated, and the use is non-commercial. See: http://creativecommons.org/licenses/by-nc/4.0/.

\section{REFERENCES}

1. Maddams J, Utley M, Møller H. Projections of cancer prevalence in the United Kingdom, 2010-2040. Br J Cancer 2012;107:1195-202.

2. Gavin AT, Drummond FJ, Donnelly C, et al. Patient-reported 'ever had' and 'current' long-term physical symptoms after prostate cancer treatments. BJU Int 2015;116:397-406.

3. Ross KM, Ranby KW, Wooldridge JS, et al. Effects of physical and mental health on relationship satisfaction: a dyadic, longitudinal examination of couples facing prostate cancer. Psychooncology 2016;25:898-904.

4. Drummond FJ, Kinnear H, O'Leary E, et al. Long-term healthrelated quality of life of prostate cancer survivors varies by primary treatment. Results from the PiCTure (Prostate Cancer Treatment, your experience) study. J Cancer Surviv 2015;9:361-72.

5. Zajdlewicz L, Hyde MK, Lepore SJ, et al. Health-related quality of life after the diagnosis of locally advanced or advanced prostate cancer: A longitudinal study. Cancer Nurs 2017;40:412-9.

6. Kerleau C, Guizard AV, Daubisse-Marliac L, et al. Long-term quality of life among localised prostate cancer survivors: QALIPRO population-based study. Eur J Cancer 2016;63:143-53.

7. Chambers SK, Sk N, Baade P, et al. Trajectories of quality of life, life satisfaction, and psychological adjustment after prostate cancer. Psycho-Oncology 2016.

8. Teleni L, Chan R, Chan A, et al. Dietary and exercise interventions to improve quality oflife, metabolic risk factors and androgen deficiency symptoms in men with prostate cancer undergoing androgen deprivation therapy. Supportive Care in Cancer 2015;23:S171.

9. Teleni L, Chan RJ, Chan A, et al. Exercise improves quality of life in androgen deprivation therapy-treated prostate cancer: systematic review of randomised controlled trials. Endocr Relat Cancer 2016;23:101-12. 
10. Fraser S, Gardner J, Livingston P. The effects of exercise on treatment side effects for prostate cancer patients receiving androgen deprivation therapy: A systematic review. BJU international 2013;112 http://onlinelibrary.wiley.com/o/cochrane/clcentral/articles/ 913/CN-01006913/frame.html.

11. Gardner JR, Livingston PM, Fraser SF. Effects of exercise on treatment-related adverse effects for patients with prostate cancer receiving androgen-deprivation therapy: a systematic review. J Clin Oncol 2014;32:335-46.

12. Taaffe DR, Newton RU, Spry N, et al. Effects of different exercise modalities on fatigue in prostate cancer patients undergoing androgen deprivation therapy: A year-long randomised controlled trial. Eur Urol 2017;72:293-9.

13. Wall BA, Galvão DA, Fatehee N, et al. Exercise improves V[Combining Dot Above]O 2 max and body composition in ADTtreated prostate cancer patients. Medicine And Science In Sports And Exercise 2017.

14. Weaver KE, Foraker RE, Alfano CM, et al. Cardiovascular risk factors among long-term survivors of breast, prostate, colorectal, and gynecologic cancers: a gap in survivorship care? J Cancer Surviv 2013;7:253-61.

15. Leach CR, Weaver KE, Aziz NM, et al. The complex health profile of long-term cancer survivors: prevalence and predictors of comorbid conditions. Journal of Cancer Survivorship 2015;9:239-51.

16. NICE. Prostate cancer Quality standard (QS91). Published 2015;11 www.nice.org.uk/guidance/qs91.

17 Kenfield SA, Stampfer MJ, Giovannucci E, et al. Physical activity and survival after prostate cancer diagnosis in the health professionals follow-up study. J Clin Oncol 2011;29:726-32.

18. Bonn SE, Sjolander A, Lagerros YT, et al. Physical activity and survival among men diagnosed with prostate cancer. Cancer Epidemiology Biomarkers \& Prevention 2015;24:57-64.

19. Friedenreich $\mathrm{CM}$, Wang $\mathrm{Q}$, Neilson HK, et al. Physical Activity and Survival After Prostate Cancer. Eur Urol 2016;70:576-85.

20. Westerink NL, Nuver J, Lefrandt JD, et al. Cancer treatment induced metabolic syndrome: Improving outcome with lifestyle. Crit Rev Oncol Hematol 2016;108:128-36.

21. Fisher A, Williams K, Beeken R, et al. Recall of physical activity advice was associated with higher levels of physical activity in colorectal cancer patients. BMJ Open 2015;5:e006853.

22. Fisher A, Wardle J, Beeken RJ, et al. Perceived barriers and benefits to physical activity in colorectal cancer patients. Support Care Cancer 2016;24:903-10.

23. Park JH, Lee J, Oh M, et al. The effect of oncologists' exercise recommendations on the level of exercise and quality of life in survivors of breast and colorectal cancer: A randomized controlled trial. Cancer 2015;121:2740-8.

24. Haussmann A, Gabrian M, Ungar N, et al. What hinders healthcare professionals in promoting physical activity towards cancer patients? The influencing role of healthcare professionals' concerns, perceived patient characteristics and perceived structural factors. Eur J Cancer Care 2018;27:e12853.

25. Tsiouris A, Ungar N, Haussmann A, et al. Health Care Professionals' Perception of Contraindications for Physical Activity During Cancer Treatment. Front Oncol 2018;8:98.

26. Rubin G, Berendsen A, Crawford SM, et al. The expanding role of primary care in cancer control. Lancet Oncol 2015;16:1231-72.

27. Herrett E, Thomas SL, Schoonen WM, et al. Validation and validity of diagnoses in the General Practice Research Database: a systematic review. Br J Clin Pharmacol 2010;69:4-14.

28. Faithfull S, Lemanska A, Aslet $P$, et al. Integrative review on the non-invasive management of lower urinary tract symptoms in men following treatments for pelvic malignancies. Int J Clin Pract 2015;69:1184-208.

29. Owen PJ, Daly RM, Livingston PM, et al. Lifestyle guidelines for managing adverse effects on bone health and body composition in men treated with androgen deprivation therapy for prostate cancer: an update. Prostate Cancer Prostatic Dis 2017;20:137-45.

30. Mackridge AJ, Gray NJ, Krska J. A cross-sectional study using freedom of information requests to evaluate variation in local authority commissioning of community pharmacy public health services in England. BMJ Open 2017;7:e015511.

31. George PP, Molina JA, Cheah J, et al. The evolving role of the community pharmacist in chronic disease management - a literature review. Ann Acad Med Singapore 2010;39:861-7.

32. Brown D, Portlock J, Rutter P, et al. From community pharmacy to healthy living pharmacy: positive early experiences from Portsmouth, England. Res Social Adm Pharm 2014;10:72-87.

33. Atkins $\mathrm{K}$, van Hoek AJ, Watson $\mathrm{C}$, et al. Seasonal influenza vaccination delivery through community pharmacists in England: evaluation of the London pilot. BMJ Open 2016;6:e009739.
34. Cormie P, Galvão DA, Spry N, et al. Can supervised exercise prevent treatment toxicity in patients with prostate cancer initiating androgen-deprivation therapy: a randomised controlled trial. BJU Int 2015;115:256-66.

35. Galvao DA, Spry N, Taaffe DR, et al. Effects of exercise on cardiometabolic profile of prostate cancer survivors from radar: A multicentre randomized trial. Supportive Care in Cancer 2012;20:S105.

36. Kiwata JL, Dorff TB, Schroeder ET, et al. A review of clinical effects associated with metabolic syndrome and exercise in prostate cancer patients. Prostate Cancer Prostatic Dis 2016;19:323-32.

37. Bourke L, Doll H, Crank H, et al. Lifestyle intervention in men with advanced prostate cancer receiving androgen suppression therapy: a feasibility study. Cancer Epidemiol Biomarkers Prev 2011;20:647-57.

38. Mutrie N, Doolin O, Fitzsimons CF, et al. Increasing older adults' walking through primary care: results of a pilot randomized controlled trial. Fam Pract 2012;29:633-42.

39. Medina-Perucha L, Yousaf O, Hunter MS, et al. Barriers to medical help-seeking among older men with prostate cancer. J Psychosoc Oncol 2017;35:531-43.

40. Neal RD. NICE prostate cancer clinical guideline: implications for primary care. Br J Gen Pract 2008;58:607-8.

41. Tueller SJ, Van Dorn RA, Bobashev GV. Visualization of categorical longitudinal and times series data. Methods Rep RTI Press 2016;2016. MR-0033-1602

42. Craig P, Dieppe P, Macintyre S, et al. Developing and evaluating complex interventions: the new Medical Research Council guidance. BMJ 2008;337:a1655.

43. Jones CJ, Rikli RE, Beam WC. A 30-s chair-stand test as a measure of lower body strength in community-residing older adults. Res $Q$ Exerc Sport 1999;70:113-9.

44. Harris T, Kerry SM, Victor CR, et al. A primary care nurse-delivered walking intervention in older adults: PACE (pedometer accelerometer consultation evaluation)-Lift cluster randomised controlled trial. PLoS Med 2015;12:e1001783.

45. Lauretani F, Russo CR, Bandinelli S, et al. Age-associated changes in skeletal muscles and their effect on mobility: an operational diagnosis of sarcopenia. J Appl Physiol 2003;95:1851-60.

46. Rikli RE, Jones CJ. Functional Fitness Normative Scores for Community-Residing Older Adults, Ages 60-94. J Aging Phys Act 1999;7:162-81.

47. Siconolfi SF, Garber CE, Lasater TM, et al. A simple, valid step test for estimating maximal oxygen uptake in epidemiologic studies. Am J Epidemiol 1985;121:382-90.

48. Godin G, Shephard RJ. A simple method to assess exercise behavior in the community. Can J App/ Sport Sci 1985;10:141-6.

49. Copeland JL, Esliger DW. Accelerometer assessment of physical activity in active, healthy older adults. J Aging Phys Act 2009;17:17-30.

50. Schröder H, Fitó M, Estruch R, et al. A short screener is valid for assessing Mediterranean diet adherence among older Spanish men and women. J Nutr 2011;141:1140-5.

51. Hibbard JH, Stockard J, Mahoney ER, et al. Development of the Patient Activation Measure (PAM): conceptualizing and measuring activation in patients and consumers. Health Serv Res 2004;39(4 Pt 1):1005-26.

52. Szymanski KM, Wei JT, Dunn RL, et al. Development and validation of an abbreviated version of the expanded prostate cancer index composite instrument for measuring health-related quality of life among prostate cancer survivors. Urology 2010;76:1245-50.

53. Rabin R, de Charro F. EQ-5D: a measure of health status from the EuroQol Group. Ann Med 2001;33:337-43.

54. Killip S, Mahfoud Z, Pearce K. What is an intracluster correlation coefficient? Crucial concepts for primary care researchers. Ann Fam Med 2004;2:204-8.

55. Zwarenstein M, Treweek S, Gagnier JJ, et al. Improving the reporting of pragmatic trials: an extension of the CONSORT statement. BMJ 2008;337:a2390.

56. Dossing A, Tarp S, Furst DE, et al. Interpreting trial results following use of different intention-to-treat approaches for preventing attrition bias: a meta-epidemiological study protocol. BMJ Open 2014;4:e005297.

57. Del Re AC, Maisel NC, Blodgett JC, et al. Intention-to-treat analyses and missing data approaches in pharmacotherapy trials for alcohol use disorders. BMJ Open 2013;3:e003464.

58. Wright CC, Sim J. Intention-to-treat approach to data from randomized controlled trials: a sensitivity analysis. J Clin Epidemiol 2003;56:833-42.

59. Papp KA, Fonjallaz P, Casset-Semanaz F, et al. Approaches to reporting long-term data. Current medical research and opinion 2008;24:2001-8. 
60. Shephard RJ. PAR-Q, Canadian home fitness test and exercise screening alternatives. Sports Med 1988;5:185-95.

61. Jacob C. Statistical Power Analysis for the Behavioral Sciences. 2nd Edn. New York, USA: edLawrence Erlbaum Associates, 1988.

62. Carter A, Humphreys L, Snowdon N, et al. Participant recruitment into a randomised controlled trial of exercise therapy for people with multiple sclerosis. Trials 2015;16:468.

63. Lindblad AS, Zingeser P, Sismanyazici-Navaie N. Incentives and barriers to neurological clinical research participation. Clin Investig 2011;1:1663-8.

64. Newington L, Metcalfe A. Factors influencing recruitment to research: qualitative study of the experiences and perceptions of research teams. BMC Med Res Methodol 2014;14:10.

65. Sussman J, Baldwin LM. The interface of primary and oncology specialty care: from diagnosis through primary treatment. $J$ Natl Cancer Inst Monogr 2010;2010:18-24.

66. Pai H, Bender J, Tong C, et al. 196: What are the unmet information and supportive care needs of canadian prostate cancer patients?. Radiotherapy and Oncology 2016;120:S72.

67. Watson E, Shinkins B, Frith E, et al. Symptoms, unmet needs, psychological well-being and health status in survivors of prostate cancer: implications for redesigning follow-up. BJU Int 2016;117:E10-E19.

68. Bourke L, Smith D, Steed L, et al. Exercise for Men with Prostate Cancer: A Systematic Review and Meta-analysis. Eur Urol 2016;69:693-703.
69. Bourke L, Homer KE, Thaha MA, et al. Interventions to improve exercise behaviour in sedentary people living with and beyond cancer: a systematic review. Br J Cancer 2014;110:831-41.

70. Galvão DA, Newton RU, Gardiner RA, et al. Compliance to exerciseoncology guidelines in prostate cancer survivors and associations with psychological distress, unmet supportive care needs, and quality of life. Psychooncology 2015;24:1241-9.

71. . Public Health England (PHE): Physical Activity. 2018 https:// fingertips.phe.org.uk/profile/physical-activity (Accessed June 2018).

72. Rejeski WJ, Marsh AP, Brubaker PH, et al. Analysis and interpretation of accelerometry data in older adults: The LIFE study. $J$ Gerontol $A$ Biol Sci Med Sci 2016;71:521-8.

73. O'Donovan G, Blazevich AJ, Boreham C, et al. The ABC of physical activity for health: a consensus statement from the british association of sport and exercise sciences. J Sports Sci 2010;28:573-91.

74. Barisic A, Leatherdale ST, Kreiger N. Importance of frequency, intensity, time and type (FITT) in physical activity assessment for epidemiological research. Can J Public Health 2011;102:174-5.

75. Amireault S, Godin G, Lacombe J, et al. The use of the godinshephard leisure-time physical activity questionnaire in oncology research: A systematic review. BMC Med Res Methodol 2015;15:60.

76. Lubans DR, Plotnikoff RC, Jung M, et al. Testing mediator variables in a resistance training intervention for obese adults with type 2 diabetes. Psychol Health 2012;27:1388-404.

77. Short CE, James EL, Girgis A, et al. Move more for life: the protoco for a randomised efficacy trial of a tailored-print physical activity intervention for post-treatment breast cancer survivors. BMC Cancer 2012;12:172 